\title{
From Stuttering and Stammering to the Diagram: Deleuze, Bacon and Contemporary Art Practice
}

\author{
Simon O'Sullivan Goldsmiths, University of London
}

\begin{abstract}
This article attends to Deleuze and Guattari's idea of a 'minor literature' as well as to Deleuze's concepts of the figural, probe-heads and the diagram in relation to Bacon's paintings. The paper asks specifically what might be usefully taken from this Deleuze-Bacon encounter for the expanded field of contemporary art practice.
\end{abstract}

Keywords: Francis Bacon, figural, diagram, contemporary art, minor literature, probe-head

\section{Minor Literature}

Deleuze and Guattari's concept of a minor literature (at least as it is laid out in Kafka: Towards a Minor Literature from where the following definition has been condensed [see Deleuze and Guattari 1986: 16-18]) involves three components: 1 . The foregrounding of the affective and intensive quality of language or its operation on an asignifying register. A minor literature stutters and stammers the major. It breaks with the operation of 'order-words'. It 'stops making sense'. 2. The always already political nature of such literature. A minor literature is always connected to the wider social milieu and not fixated on the domestic/Oedipal. 3. Its specifically collective character. A minor literature is always a collective enunciation. In fact, a minor literature works to pave the way for a community-sometimes a nation-yet to come. This is a minor literature's future orientation.

Each of these components of a minor literature, I would argue, can be 'applied' to contemporary art practice (and I think operate as a corrective to any simple affirmation of 'the new' as it is incarnated in the 
commodity form). Elsewhere I have attended to the third point above, which seems to me to be a particularly useful way of thinking through many of the most interesting of today's art practices and their mode of effectivity, as it were. To briefly repeat that point here: such practices are not made for an already existing audience, but to call forth-or invoke-an audience. They do not offer more of the same. They do not necessarily produce 'knowledge'. They do not offer a reassuring mirror reflection of a subjectivity already in place. With such art 'the people are missing', as Deleuze might say. In fact, I would argue, the operating field of these practices can be thought of as the future and, as such, the artists in question here operate as kind of prophets. We might even say traitor prophets, in so far as they perform a treachery in relation to our more dominant affective/signifying regimes (that is to say, consensual reality).

All of this gives such art a utopian function inasmuch as part of its being is somehow located elsewhere. Importantly, and following Deleuze, and Deleuze and Guattari, we can understand this as a specifically immanent utopia-intrinsically connected to the present, made out of the same materials, the same matter (after all what else is there?) but calling 'for a future form, for a new earth and people that do not yet exist' (Deleuze and Guattari 1994: 108). This last quotation is from an argument Deleuze and Guattari make in relation to philosophy, and to the creation of concepts; however, it seems to me it is equally applicable to a minor literature, and indeed to contemporary art practice (not least given the fact that art practice post-Duchamp has increasingly concerned itself with the conceptual, and indeed, in some cases, with the invention of concepts). In passing, I think we could make the argument that Bacon's paintings are traitor paintings in this sense. Certainly they are different to the other objects that surround us and constitute our everyday habitual milieu. Bacon's paintings might also be thought of as future-orientated in that they are not merely of the present in the sense of being easily readable by our present subjectivity as it is. They call something forth from within us, in fact something that is not just another reading/interpretation of the paintings in question. This affective response or reaction might involve a certain interest or excitement, a point of inspiration perhaps (and Spinoza's notion of a productive, joyful encounter would be pertinent here), but it might also be a certain horror or disgust, even an irritation or boredom. These last two often mask the fact that something has been encountered that in some way challenges a given subjectivity. They operate as defensive mechanisms. As far as art goes reactions such as these might indicate that we are at a limit point or edge-and that if we can stay with these uncomfortable affects then 
something, finally, might happen. We might say then that this future orientation of art as I have been calling it opens us up to what we might become.

So much for this third modality of a minor literature. Below I want also to focus on the first characteristic of the latter-its operation on an intensive register. To repeat, for Deleuze and Guattari, a minor literature foregrounds asignification or simply the intensive aspects of language. It counteracts the operation of order-words and the exercise of power this involves by breaking language open to a howling outside/inside. It is these moments of noise-or glitches as we might call them-that free language from itself, at least, from its signifying self, by putting it into contact with other forces. This is an experimentation with, and from within, language. A rupturing of representation. A breaking of the habit of 'making sense', of 'being human'. We can perhaps begin to see here the connections with Bacon.

In more technical terms, such a stuttering and stammering of language operates to produce what I would term an affective-event that in itself can produce what Guattari calls a 'mutant nuclei of subjectification' and thus the possibility of 'resingularisation' (a reordering of the elements that make up our subjectivity) (Guattari 1995: 18). In fact, when attending to this event in his own writings Guattari turns to Mikhail Bahktin and writes of the 'detachment of an ethico-aesthetic "partial object" from the field of dominant significations' that 'corresponds both to the promotion of a mutant desire and to the achievement of a certain disinterestedness' (Guattari 1995: 13). The partial object here operates as a point of entry into a different incorporeal universe. A point around which a different kind of subjectivity might crystallise. Crucially, and as Guattari remarks, this operation must involve a certain disinterestedness (Guattari is indebted to Kant in this sense). We might say that the listener-or spectator-must respond to the glitch, the affective-event, as an event, as the bearer of the potentiality of something else. Put simply, one must, in order that this procedure work, be open to the possibility of something different occurring. This, I think, is crucial. The artwork-or the work that art demands of us-involves an active engagement, a participation as it were. Without the latter even the most seemingly radical work will remain inoperative. The glitch then, I would argue, is co-produced through object and subject-in fact, it names a passage between the two. This last point would be to bring Guattari's expanded notion of art briefly laid out above, and indeed the central notion of becoming in A Thousand Plateaus, into conjunction with the apparently more conservative 'version' of art given in What is Philosophy?, where 
art is seen as precisely the place of 'a passing between things'. As Deleuze and Guattari remark in the latter volume: 'Life alone creates such zones where living beings whirl around, and only art can reach and penetrate them in its enterprise of co-creation' (Deleuze and Guattari 1994: 173).

Deleuze and Guattari's work on the notion of a minor literature and specifically, here, the necessity of stammering and stuttering a major language, or the foregrounding of what I have been calling the glitch, is then a highly productive text for thinking the field of contemporary art in its conservative and in its more expanded form (we might say, within painting [as we shall see with Bacon] but also within video for example [that often stutters and stammers 'reality' and indeed the major language of film]). Such affective stammering operates as a kind of singularity that in itself counteracts already existing affective/signifying regimes, whilst at the same time, crucially, opening up a gap within these all too familiar series and circuits of knowledge/information. A gap which we might also configure here as a form of non-communication. This is to bring art close to what Deleuze calls (and calls for), in his 'Postscript on Societies of Control':

Maybe speech and communication have become corrupted. They're thoroughly permeated by money-and not by accident but by their very nature. Creating has always been something different from communicating. The key thing might be to create vacuoles of non-communication, circuit breakers so we can elude control. (Deleuze 1995: 175)

Art is not, I would argue, ultimately concerned with knowledge-or, at least, with what passes for knowledge within our everyday knowledgeeconomy (simply, information). It is not 'useful' in this sense. Indeed, even those so-called art practices that seek to produce counterknowledge can become caught by the very thing they attempt to work against. Such practices necessarily have to work on the same terrain as it were-and thus utilise the same terms. Art, it seems to me, might be better thought of as an event that interrupts knowledge-that breaks information. In fact, art is one of the very few things we have left that is able to creatively make this break.

We might also understand these moments or rupturing events in Bergsonian terms as opening further the gap between stimulus and response that defines us as human (the complexity of the nervous system, which allows a multiplicity of different pathways for stimulus-response, determines a hesitation-or gap-in that response). This is to identify a certain slowness, even a stillness, which might work against the incessant speed of contemporary 'life'. For Bergson, this gap opens us up to the 
pure past-a kind of ontological background to ourselves. It is through this gap that we become creative rather than reactive creatures (see Bergson 1991: 101-2). This is the very definition of freedom, at least freedom from habit or simply the (impasses of the) present plane of existence.

Another way of understanding this potential of the glitch-following Guattari-is that it operates as a point of indeterminacy, and, as such, opens up the possibility of a multiplicity of subsequent pathways and thus a multiplicity of possible worlds. We might say in fact that the glitch always contains within it the germ of a new world. Indeed, I would argue, it is this functioning as a point of indetermination that gives much contemporary art its inspirational, we might even say hopeful tenor. Such glitches - or breaks in the typical-are a kind of reverse-technology in that they offer an escape from the manipulation performed by those other affective assemblages that increasingly operate in a parallel logic to art. I am thinking here of the complex utilisation of affect, specifically by the mass media that increasingly operates on a self-consciously affective register - as a kind of nervous system - utilising the temporally indeterminate aspect of the event in an ever expanding exercise of power (what we might call a politics of pre-emption, or simply, the colonisation of the virtual).

We might say then that the glitch names two moments or movements. To break a world and to make a world. In fact these two are never really divorced from one another: to dissent means invariably to affirm some where/thing else. To affirm an elsewhere we have to turn from that which is already here. The glitch is then a moment of critique, a moment of negation - but also a moment of creation and of affirmation. Indeed, the glitch-in whichever regime it operates and ruptures - is the 'sound' of this something else, this something different attempting to get through. To end this first section then, we can return to the artist as the one who specifically uses this logic of the glitch. The artist as traitor prophet names a twin orientation: the betrayal of one world and the affirmation of a world-yet-to-come.

\section{Deleuze-Bacon}

I want now to shift sideways, before returning to this idea of stuttering and the glitch, and look at Deleuze's book on Bacon and at a number of concepts Deleuze 'invents' there to think Bacon's paintings. As with the above section I am particularly interested here in how these 
concepts - and the paintings - attempt to undo representation, and how we might extend their workings to the field of contemporary art in general.

Firstly then, the figural. The figural for Deleuze-Bacon is that which deforms, or does violence to, the figurative. We can understand the latter here as the typical way we are represented and represent ourselves within the world. Those forms that reassure us of our identity. Indeed, for Deleuze, representation is not solely a type of art, as it were, but the very means by which we constitute ourselves as an organism and as a subject in the world. To quote Deleuze:

If representation is related to an object, this relation is derived from the form of representation; if this object is the organism and organisation, it is because the form of representation is first of all organic in itself, it is because the form of representation first of all expresses the organic life of the man as subject. (Deleuze 2003: 126)

The figural achieves this disruption, firstly, through a mechanism of isolation. The figure is presented as a 'matter-of-fact', detached from narration or any illustrative function. To quote Deleuze again:

Isolating the figure will be the primary requirement. The figurative (representation) implies the relationship of an image to an object that it is supposed to illustrate; but it also implies the relationship of an image to other images in a composite whole which assigns a specific object to each of them. Narration is the correlate of illustration. A story slips into, or tends to slip into, the space between the two figures in order to animate the illustrated whole. (Deleuze 2003: 3)

Isolation then is a method for breaking with a certain use of images in our world - the way in which they tend to be mobilised for a certain end, almost always to sell us something (witness advertising). In passing, and with a nod to Guattari's writings on the Readymade, we might expand this requirement of isolation out to the wider field of contemporary art in general. An object might be detached from its habitual mode of circulation and specifically its position within capitalist relations of exchange. We might say simply, that it is, in one sense, rendered inoperative, placed as it is within the frame of art.

However, to return to Bacon, this isolation is only one moment in a process, for the isolated figure also operates as a point of departure for deterritorialisations, for a moving beyond the figure. In this sense the figural is a kind of in-between the figurative and the non-figurative. Put differently, the figural involves a becoming of the figure. A becominganimal ('in place of formal correspondences what Bacon's painting 
constitutes is a zone of indiscernability or undecideability between man and animal' [Deleuze 2003: 21]), and ultimately a becomingimperceptible ('whatever its importance becoming-animal is only one stage in a more profound becoming-imperceptible in which the figure disappears' [Deleuze 2003: 27]).

To return to my digression on the Readymade, and following Guattari once more, we might say that the object isolated from a given series works as a trigger point to open up other 'incorporeal universes of value' (and no doubt, given the increasing emphasis on productivity and speed within our information age, this isolation and opening will involve the type of slowness I mentioned above). Hence Guattari's understanding of the Readymade-laid out in his essay 'Ritornellos and Existential Affects' - as that object which has been taken out of a normal series thus allowing the latter to be put to work in a different manner:

Marcel Duchamp's Bottlerack functions as the trigger for a constellation of referential universes engaging both intimate reminiscences (the cellar of the house, a certain winter, the rays of light upon spider's webs, adolescent solitude) and connotations of a cultural or economic order-the time when bottles were still washed with the aid of a bottle wash... (Guattari 1996: 164)

It is this power of art to access these other universes and other times away from a narrow and alienated present that, we might say, is the time of art.

Secondly, probe-heads. We can see the above becoming-animal in relation to Bacon's treatment of heads where, in the terms of A Thousand Plateaus, Bacon attempts to disrupt the processes of faciality, understood here as that abstract machine of modernity that produces signifiance (the white wall) and subjectification (the black hole). To quote Deleuze and Guattari from the latter volume:

if human beings have a destiny, it is rather to escape the face, to dismantle the face and facialisations, to become imperceptible, to become clandestine, not by returning to animality, nor even by returning to the head, but by spiritual and special becomings-animal, by strange true becomings that get past the wall and get out of the black holes. (Deleuze and Guattari 1988: 171)

Bacon's heads are probe-heads in this precise sense, lines of escape from the face and from faciality. Crucially, they are not a return to some kind of primitive pre-faciality. They are in fact an escape that takes place from within the terrain of the face itself, a kind of stammering from within. Of course, probe-heads need not necessarily be pictures of heads but rather any device that disrupts faciality, for the latter applies not 
just to heads but to all of the mechanisms that produce signifiance and subjectivity (from faces and landscapes within painting to facialisation and lanscapification within the world). To quote Deleuze and Guattari once more:

You will be pinned to the white wall and stuffed in the black hole. This machine is called the faciality machine because it is the social production of the face, because it performs the facialisation of the entire body and all its surroundings and objects, and the landscapification of all worlds and milieus. (Deleuze and Guattari 1988: 181)

A probe-head is then that which explores the terrain beyond the face, the terrain from which the face is nothing more than an extraction or crystallisation. Probe-heads are in this sense a move into chaos. Probe-heads are those devices 'that dismantle the strata in their wake, break through walls of signifiance, pour out of the holes of subjectivity, fell trees in favour of veritable rhizomes, and steer the flows down lines of positive deterritorialisation or creative flight' (Deleuze and Guattari 1988: 190). They are, however, not just destructive, but, as the name suggests, productive of other, stranger and more fluid modes of organisation: 'Beyond the face lies an altogether different inhumanity: no longer that of the primitive head, but of 'probeheads'; here, cutting edges of deterritorialisation become operative and lines of deterritorialisation positive and absolute, forming strange new becomings, new polyvocalities' (Deleuze and Guattari 1988: 190-1). As well as being a name for Bacon's portraits (and indeed his other paintings), 'probe-heads' might also be a useful name for more experimental, non-traditional art practices, or indeed for other practices - of living differently-not normally considered 'art'. Such practices might not seem to be de-facialisations, but with the systems of facialisation becoming increasingly complex (one thinks here again of the mass media and especially of new communications technologies) then the lines of flight from these will themselves become increasingly complex and unfamiliar, as will the territories produced on the other side of the 'white wall'. A case study of this new production of subjectivity might be collective and collaborative practices, those that deliberately dissent-or simply turn away from - the production of individualist and atomised subjectivities and other typical capitalist formations.

Importantly, probe-heads do not arrive from some other place. They are in fact made from the same stuff as faces. Indeed, we might say that the same (capitalist) machines that produce probe-heads also produce faces. The latter being subjectivities and assemblages that are 'useful', 
the former often appearing as redundancies or dead ends. We have here a definition of sorts of art: it involves a kind of super-productivity arising from what appears, on the face of it as it were, to be non-productive.

Third, and finally, the diagram. For Deleuze-Bacon it is the diagram that enables this deterritorialisation of the face and the production of the 'body without organs' (the latter understood here as that which lies 'under' the organism/organisation [Deleuze 2003: 50]). In painting, and specifically Bacon's painting, the diagram involves the making of random marks that allow the figural to emerge from the figure. 'The diagram is... the operative set of asignifying and nonrepresentative lines and zones, line-strokes and colour-patches' (Deleuze 2003: 101). We might apply this rule of the diagram to other kinds of modern and contemporary art-practices that necessarily involve this play with chance, this contact and utilisation with that which goes beyond conscious control, if only to circumnavigate the reproduction of justmore-of-the-same. It would be an interesting project to identify how specific artists incorporate this lack of control 'into' their practice, or simply, how they contact and somehow 'use' that which is outside them 'selves'. How, for example, they might mobilise chance (and perhaps error) in the production of something new.

Here random occurrences are ontologically constitutive of art (and not an accident that befalls it). Indeed, an art practice-rather than a practice that just produces products - is always open to an outside in this sense. It needs to have a certain cohesiveness and form, but equally must be able to access a certain formlessness, as it were (simply put, it must have points of collapse). It is in this sense that art can never be wholly predetermined or worked out in advance but must involve this productive encounter with chaos (it is also in this sense that the artist seeks to make work that speaks back to him or her, as it were, or, in the painter Gerhard Richter's terms, 'that something will emerge that is unknown to me, which I could not plan, which is better, cleverer, than I am' [Richter, quoted in Gidal 1993: 47]).

The diagram is then 'a chaos, a catastrophe, but it is also a germ of order or rhythm. It is a violent chaos in relation to the figurative givens, but it is a germ of rhythm in relation to the new order of the painting' (Deleuze 2003: 102). The diagram is rhythm emerging from chaos, the manipulation of chance to suggest the 'emergence of another world' (Deleuze 2003: 100). Again, all sorts of art practices might be said to produce rhythmic worlds in this sense, worlds hitherto unseen but always produced from within the seen. Art is the production of worlds (the figural) that sit between that which is known (the figurative) and 
that which is unknown (chaos): 'the law of the diagram, according to Bacon, is this: one starts with a figurative form, a diagram intervenes and scrambles it, and a form of a completely different nature emerges from the diagram, which is called the Figure' (Deleuze 2003: 156). Art, when it really is art, is always located at the edge of things in this sense. It faces, as it were, in two directions. It is a bridge, or again, a passage between.

This is, however, not all without its dangers. Indeed, for DeleuzeBacon there are two 'wrong' positions as it were, which the middle way of the figural must avoid. Figuration (narration and illustration, which is to say representation), but also the absolute deterritorialisation of the figure (the move to total abstraction). We might call these the twin dangers of moving too slow-of remaining within representation-but also of moving too fast and ultimately following a line of abolition. Figuration operates through cliché, understood as that which surrounds us everyday: 'We are besieged by photographs that are illustrations, by newspapers that are narrations, by cinema-images, by television-images' (Deleuze 2003: 87). These are the clichés - physical, though there are also psychic ones ('ready-made perceptions, memories, phantasms' [Deleuze 2003: 87]) that fill the canvas even before the artist has dipped his brush (for Deleuze-Bacon, unlike Clement Greenberg for example, the canvas is not empty, but always already full, teeming as it were with virtualities). Another way of understanding these clichés is as habits; habits of sight-and also of thought. Art opposes the latter with its own logic of difference.

The other way, abstraction, can be divided further into two tendencies: 1. Pure or geometric abstraction, which elevates the optical and ultimately returns to figuration inasmuch as it contains a code (visual and spiritual) or, to say the same differently, passes through the brain (as is the case, Deleuze argues, with Kandinsky) (Deleuze 2003: 104-5). In this regard, the same criticism can be made against both figurative painting and abstract painting: 'they pass through the brain, they do not act directly on the nervous system, they do not attain the sensation, they do not liberate the Figure - all because they remain at one and the same level' (Deleuze 2003: 36). This is a signifying art waiting to be read. 2. Action painting, as paradigmatically the case with Jackson Pollock, that provides an all-over diagram (a purely haptic space) but in so doing, according to Deleuze-Bacon, loses its capacity to act on our nervous system (such painting is not controlled enough) (Deleuze 2003:109). The figural avoids these, although it is, according to Deleuze, no less radical in its own path. 
In concluding this second part of my paper we might say then that the figural involves a not-too-fast but also a not-too-slow deterritorialisation of the figure-a rupturing of the latter so as to allow something else to appear, or to be heard 'behind' the figure as it were. The figural might seem less radical than other avant-garde techniques, other attempts at bringing art into life (one thinks here of not just the many movements of modernism but also of their stuttering and stammering manifestos...). There is indeed a cautious aspect to Bacon's practice of painting-a certain control that accompanies the wildness. The same might be said of Deleuze who, in his writings, practises an 'art of dosages'. It might be argued however that it is only through this caution, through this careful engagement with the matter of representation, that the line of flight from representation can be actually located. To quote Deleuze and Guattari themselves specifically on this methodological point:

This is how it should be done: Lodge yourself on a stratum, experiment with the opportunities it offers, find an advantageous point on it, find potential movements of deterritorialisation, possible lines of flight, experience them, produce flow conjunctions here and there, try out continuums of intensity segment by segment, have a small plot of new land at all times. It is through a meticulous relation with the strata that one succeeds in freeing lines of flight.

(Deleuze and Guattari 1988: 161)

\section{Conclusion}

In conclusion, we might say that the figural within Bacon parallels Deleuze's own philosophical project (and even more particularly the joint project with Guattari as laid out in A Thousand Plateaus) of thinking beyond the human. The human is to be understood here as a habitual mode of being (a representational mode). Both projects involve less a simple abandoning of the figure or of the human (that is, a complete disruption/abolition), but rather a kind of stretching or twisting of the latter. A rupturing that allows for the releasing of forces from within and the contact of forces that are without (both in fact being the same operation). Both Bacon and Deleuze are specifically mannerist in this sense (Deleuze 2003: 161). Both are interested in accessing the figural 'behind' the figure; the invisible 'behind' the visible.

We are now in a position to attempt an articulation of the connections between the notion of the diagram in painting and the intensive functioning of a minor literature: both involve a stuttering and stammering-of the figurative, of language-of representational modes. Both also involve the utilisation of these glitches as points 


\section{Simon O'Sullivan}

of indeterminacy that might finally allow something new, something different, to emerge. Indeed, although specific in many senses to Kafka's writings and to Bacon's paintings, both are, I think, incredibly productive concepts, not least in thinking through the effectivity of the expanded field of contemporary art practice as it exists today.

\section{References}

Bergson, Henri (1991) Matter and Memory, trans. Nancy Margaret Paul and W. Scott. Palmer, New York: Zone Books.

Deleuze, Gilles (1995) Negotiations: 1972-1990, trans. Martin Joughin, New York: Columbia University Press.

Deleuze, Gilles (2003) Francis Bacon: The Logic of Sensation, trans. Daniel W. Smith, London: Continuum.

Deleuze, Gilles and Félix Guattari (1986) Kafka: Towards a Minor Literature, trans. Dana Polan, Minneapolis: University of Minnesota Press.

Deleuze, Gilles and Félix Guattari (1988) A Thousand Plateaus: Capitalism and Schizophrenia, trans. Brian Massumi, London: Athlone Press.

Deleuze, Gilles and Félix Guattari (1994) What is Philosophy?, trans. Hugh Tomlinson and Graham Burchell, London: Verso.

Gidal, Peter (1993) 'Endless Finalities', Parkett: Gerhard Richter, 35, pp. 45-8.

Guattari, Félix (1995) Chaosmosis: An Ethico-aesthetic Paradigm, trans. Paul Bains and Julian Pefanis, Sydney: Power Publications.

Guattari, Félix (1996) 'Ritornellos and Existential Affects', in Gary Genosko (ed.), The Guattari Reader, Oxford: Basil Blackwell, pp. 158-71. 